\title{
Ultra-High Temperature Ceramics: Materials for Extreme Environments
}

William G. Fahrenholtz ${ }^{*}$ and Greg E. Hilmas

Department of Materials Science and Engineering

Missouri University of Science and Technology, Rolla, MO 65049

\begin{abstract}
This paper identifies gaps in thepresent state of knowledge and describes emerging research directions for ultra-high temperature ceramics. Borides, carbides, and nitrides of early transition metals such as $\mathrm{Zr}$, Hf, Nb, and Ta have the highest melting points of any known compounds, making them suitable for use in extreme environments.Studies of synthesis, processing, densification, thermal properties, mechanical behavior, and oxidation of ultra-high temperature ceramics have generated a substantial base of knowledge, but left unanswered questions. Emerging research directions include testing/characterization in extreme environments, composites, computational studies, and new materials.
\end{abstract}

Keywords:ceramics, extreme environments, borides, carbides, nitrides

\section{Introduction}

Ultra-high temperature ceramics (UHTCs)are an emerging class of materials that have the potential for use in extreme environments. ${ }^{1,2}$ Most often, UHTCs are defined as compounds that have melting points above $3000^{\circ} \mathrm{C}$ (Figure 1). ${ }^{3}$ Several alternative definitions have been proposed with the most pragmatic being that UHTCs are ceramic materials that can be used for extended times at temperatures above $1650^{\circ} \mathrm{C} .{ }^{4}$ However, none of these definitions captures the

\footnotetext{
* Corresponding author email address billf@mst.edu
} 
wide range of extreme conditions in which UHTCs may be used.Chemically, nearly all UHTCs are binary compounds in which boron, carbon, or nitrogen combine with one of the early transition metals (TMs) such as $\mathrm{Zr}, \mathrm{Hf}, \mathrm{Ti}$, Nb, and Ta. ${ }^{5}$ The strong covalent bonds between the TMs and B, C, or N result in compounds with high hardness, stiffness, and melting temperature. ${ }^{6}$ These compounds also exhibit higher electrical and thermal conductivities than oxide ceramics due to varying degrees ofmetallic bond character.This intriguing combination of metal-like and ceramic-like properties allowUHTCsto survive extreme temperatures, heat fluxes, radiation levels, mechanical loads, chemical reactivities, and other conditions that are beyond the capabilities of existing structural materials.

Reports of the synthesis of UHTCs date back to the late 1800 s, ${ }^{7,8}$ but technological interest in these materials grew dramatically during the space race that started in the late 1950s and extended through the 1960s. At that time, groups in the Soviet Union and the U.S. were searching for materials to be used in rocket motors, heat shields, and structural components for the first generation of spacecraft. ${ }^{9,10}$ These vehicles were going to encounter heat fluxes and temperatures for durations that were beyond the capabilities of traditional approaches such as transpiration cooling, heat sinks, and convective/radiative cooling. ${ }^{11}$ The technological challenges motivated a tremendous body of research conducted by scientists includingG.V. Samsonov, H. Nowotny, E.V. Clougherty, and L. Kaufman. Publications produced by these researchers and their collaborators document fundamental understanding of the bonding, electronic structure, thermodynamic properties, mechanical behavior, phase equilibria, and oxidation response of UHTCs. After this initial surge of interest, research on these materials waned for several decades. 
Interest in UHTCs was renewed in the late 1980s, again due to aerospace applications such as scramjet propulsion, hypersonic aerospace vehicles, andadvanced rocket motors. ${ }^{4,12-15}$ For example, in the U.S., the National Aeronautics and Space Administration (NASA) and the U.S. Air Force built and flew vehicles as a means to test technologies needed for sustained hypersonic flight (Figure 2). One of the technological challenges was presented by the designs, which included sharp leading edges and control surfaces. At hypersonic speeds, the bow shock at these sharp features produces temperatures in excess of $2000^{\circ} \mathrm{C}$, heat fluxes of hundreds of Watts per square $\mathrm{cm}$, and highly reactive dissociated gas species. ${ }^{16}$ Diboride-based UHTCs were considered for these applications based on the combination of thermal conductivity, strength at elevated temperature, and oxidation resistance, ${ }^{17}$ while carbides and nitrides have received more attention for components such as nozzle throats, divert/attitude control thrusters, and nozzle liners where higher thermal and mechanical loads are encountered. $^{18}$

In this paper, continuing challenges in areas of recent research activity are identified followed by an assessment of emerging trends and an outlook for future research.

\section{Continuing Challenges}

Research on UHTCs during the past 25 years has furthered the state of knowledge in several important areas including synthesis, processing, densification, thermomechanical properties, and oxidation.Despite these advances, key gaps in the understanding of UHTCs remain. Research groups in the U.S., China, Japan, the U.K., Europe, India, and other countries have on-going efforts focused in these areas.

Most commercial UHTCs are synthesized by carbothermal reduction of the corresponding oxide. ${ }^{19,20}$ Limitations of this method include the relatively coarse particle sizes 
and substantial levels (i.e., $0.1 \mathrm{wt} \%$ or higher) of impurities including other metals, oxygen, nitrogen, and/or carbon.Despite these limitations, a majority of the recent studies of UHTCs have utilized commercial powders. Alternative synthesis methodscanproduce powders with finer particle sizes, higher purities, or controlled shapes. ${ }^{21}$ Processes based on solid-state reactions have been the most popular routes, but processes utilizingliquid or polymer precursors have been pursued to enable deposition of coatings or polymer infiltration and pyrolysis (PIP) processing of UHTC-matrix composites. Most of the liquid/polymer processes reported to date have involved two steps whereby the precursors decompose to an oxide with or without carbon/boron, which is then reacted to form the desired UHTC phase (Figure 3). ${ }^{22}$ Some recent advances have surmounted this obstacle by directly synthesizing borides or carbides in a single step. ${ }^{23}$ Continuing research challenges in synthesis include synthesizing higher purity UHTC powders, identifying mechanisms and kinetics of synthesis reactions, and designing liquid/polymer precursors that have higher ceramic yields and are less sensitive to degradation under ambient conditions.

Most often, UHTCs are processed as dry powders using conventional forming methods such as dry pressing. A limited number of studies have reported novel aspects of dispersion, ${ }^{24}$ colloidal forming, ${ }^{25}$ and plastic forming methods, ${ }^{26,27}$ revealing fundamental aspects of the surface chemistry of UHTCswhile also enabling near-net shape forming. Processing and synthesis have substantial synergy whereby improvements in synthesis that control the size, shape, or surface chemistry of UHTC powders impacts the ability to form stable dispersions and develop desired rheological properties in suspensions, pastes, or plastic masses. Very few studies have addressed the fundamental processing science of UHTCs resulting in opportunities to explore control of powder surface chemistry, produce slurries and pastes withhigh solids 
loadings, develop additive manufacturing processes, and devise aqueous processing routes that do not increasethe oxygen impurity content of the resulting ceramics.

Sintering of non-oxide ceramics, and particularly UHTCs, involves a competition between densifying and coarsening mechanisms. ${ }^{28}$ The presence of oxygen and other impurities promotes coarsening mechanisms that produce porosity trapped within grains, exaggerated grain growth, or other phenomena, which prevent ceramics from reaching full relative density (Figure 4). ${ }^{29}$ Finer starting particle sizes can enhance sintering, but oxygen contents must be below certain critical levels for full densification. While pressure-assisted methods such as hot pressing, hot isostatic pressing, and spark plasma sintering are the most common methods for densification, pressureless sintering can be accomplished in some systems through the use of additives. ${ }^{30-32}$ Despite practical knowledge for densification, only a few publications have reported detailed information on the fundamental transport mechanisms for densification or the kinetics of sintering processes leaving ample room for additional basic research in these areas.

A multitude of studies have described the room temperature thermal and mechanical properties of UHTCs with the most important properties being strength, hardness, elastic constants, thermal conductivity, and fracture toughness. Most of these studies have reported properties fora single ceramic without identifying fundamental factors related to composition, microstructure, porosity, impurities, etc. that control observed behavior.Presentation of properties without understanding of structure-property relations presents a particular challenge for UHTCs. A single report of poor properties or sub-standard performance in a ground test can turn potential users against an entire class of materials, even if the material in question failed due to extrinsic factors that could have been addressed had the root cause of failure been studied.Systematic studies have elucidated microstructure-mechanical property relationships and 
identified strength-limiting flaws to the extent that ceramics with desired properties can be designed by controlling grain size for nominally pure, fully dense $\mathrm{ZrB}_{2}$ or $\mathrm{SiC}$ cluster size in $\mathrm{ZrB}_{2}$-SiC ceramics. Studies have also begun to address the fundamental factors that are responsible for the wide variety of room temperature thermal conductivities reported for $\mathrm{ZrB}_{2^{-}}$ based ceramics (Figure 5) and other UHTCs. ${ }^{33-36}$ Additional research is needed to isolate fundamental factors that control thermal and mechanical behavior for compositions other than $\mathrm{ZrB}_{2}$ or $\mathrm{ZrB}_{2}$-SiC, examine elevated temperature structure-property relationships, andreport intrinsic properties of UHTCs.

Oxidation behavior, or, more broadly, resistance to aggressive chemical environments, is critical in the extreme environments that might be encountered by UHTCs include oxidation above $1600^{\circ} \mathrm{C}$, reaction dissociated air behind a bow shock, or corrosion in the exhaust plume of a solid rocket motor.Reactions between TM compounds of B, C, and N and oxygen are highly favorable at all temperatures. Additives commonly used to improve oxidation resistance include the addition of Si-rich compounds with $\mathrm{SiC}$ or $\mathrm{MoSi}_{2}$ being the most common. These additives improve oxidation resistance by promoting passive oxidation through the formation of a silicarich scale. However, silica scales are only effective in certain regimes of temperature, total pressure, and external gas velocity.Additives such as $\mathrm{SiC}$ that improve oxidation resistance in conventional oxidation tests can have a detrimental effect in extreme environments by generating gaseous reaction products through active oxidation. ${ }^{37}$ Under the most extreme conditions, the TM oxide provides the protection. In general, borides have superior oxidation resistance at temperature up to $\sim 1700^{\circ} \mathrm{C}$ while carbides perform better at higher temperatures.Significant progress has been made toward understanding both the thermodynamics and kinetics of the oxidation of diboride-based UHTCs (Figure 6). ${ }^{38}$ In addition, oxidation behavior of the carbides 
has also been reported.The main challenges for oxidation studies are to understand behavior in extreme environments that are relevant to different applications, predicting the effects of composition and microstructure on oxidation without prior experimental studies, and designing UHTC structures that are thermomechanically stable and resistant to oxidation.

\section{Emerging Trends}

Several exciting new research directions are emerging for UHTCs. These studies draw on the base of knowledge established in historic studies or recent research to address challenges that stand in the way of UHTCs reaching their full potential for use in extreme environments. For this paper, emerging research has been grouped into theme areas of testing/characterization in extreme environments, composites, computational studies, and new materials. While these themes do not capture all of the efforts that are in progress, they provide a snapshot of some of the significant research challenges for UHTCs.

A vast majority of the characterization and testing of UHTCs is carried out under ambient conditions (i.e., near room temperature and atmospheric pressure) even though applications of these materials will expose them to extreme environments such as temperatures of $2000^{\circ} \mathrm{C}$ or above, heat fluxes of hundreds of $\mathrm{W} / \mathrm{m} \bullet \mathrm{K}$, dissociated gases, etc. Unfortunately for the research community, much of the testing that has been done in relevant environments is restricted or classified since those environments and the test results could reveal the capabilities and weaknesses of defense systems or information that could be used to proliferate nuclear weapons technology.The promise of improved performance under extreme conditions is often made by extrapolating data collected at near-ambient conditions without accounting for potential nonlinear behavioral trends, which could be caused by phenomena such as phase changes, creep, softening of grain boundary/impurity phases, sub-critical crack growth, or stress-induced 
microcracking.A few research laboratories around the world have established the ability to test materials under extreme conditions. For example, our laboratory at the Missouri University of Science and Technologycan test mechanical properties (strength, elastic modulus, fracture toughness), thermal properties (thermal diffusivity and heat capacity), and electrical conductivity from room temperature up to $2000^{\circ} \mathrm{C}$ or higher. ${ }^{39-44}$ Likewise, research groups at the Harbin Institute of Technology, ${ }^{45,46}$ Imperial College London, ${ }^{47}$ University of Birmingham, ${ }^{48}$ and University of Arizona ${ }^{49}$ have all established testing capabilities thatreproduce one more types of extreme environments. In addition, a team at University of California, Berkeley has developed a unique chamber that allows in-situ observation of mechanical tests at ultra-high temperatures. ${ }^{50}$ Without a doubt, the ability to produce and sustain extreme conditions in test facilities is difficult, particularly when attempting to create combined environments to evaluate the influence of multiple stresses (e.g., mechanical load and heat flux). Fundamentally, most sensors do not operate in extreme conditions so accurate characterization of environments and material responses is difficult.The ability to test and characterize materials under extreme conditions is needed not only to understand the fundamental behavior under these conditions, but also to enable collection of data to verify simulations of performance for UHTCs in specific applications that involve one or more extreme environments.

Several laboratories around the world have the ability to simulate conditions associated with hypersonic flight and atmospheric re-entry using plasma wind tunnels, inductively coupled plasma systems, arc heaters, or similar systems. ${ }^{51-} 59$ While some of these are open to academic researchers, results tend to be restricted if they are generated at facilities operated by government agencies and companies that reproduce conditions for specific flight profiles.To overcome issues of cost and access, groups have built oxy-acetylene torch rigs for testing under high heat 
flux/ablation conditions. ${ }^{60-63}$ Both types of tests are vital to demonstrate that UHTCs can survive the conditions associated with hypersonic flight, rocket propulsion, atmospheric re-entry, etc. However,the reported studies tend to evaluate a single material under a specific set of conditions, which does not produce significant insight into the fundamental understanding of the material response to the extreme conditions. For example, ablation or recession rates are often calculated for a UHTC based on a single exposure condition, but the response of UHTCs to these environments is complex and inherently non-linear. Hence, calculation of an ablation rate from a single exposure is extremely suspect. Additional limitations of these tests are that they do not directly evaluate any of the fundamental properties of the materials and the environments, though extreme, do not reproduce those that will be encountered in use. As a result, tests in relevant environments are under-utilizedby basic researchers, creating an opportunity for fundamental research on the complex responses (i.e., coupled thermal, mechanical, chemical, etc.)exhibited by materials in extreme environments.

Continuous fiber reinforced UHTCs are needed because UHTCs are brittle and exhibit ceramic like mechanical behavior. As a result, exposure to extreme temperature, heat fluxes, strain rates, etc., can produce catastrophic failure. For example, monolithic ceramics tested in simulated atmospheric re-entry conditions often fail during testing due to thermal shock. ${ }^{59}$ Composites in which UHTC matrices are reinforced by continuous fibers are attractive because of the improved fracture toughness and non-catastrophic failure behavior. Several groups have begun to investigate UHTC-based composites. ${ }^{64-}{ }^{70}$ Some of the continuing technical challenges include formulating liquid/polymer-based precursors for UHTC matrices, producing fibers capable of withstanding extreme conditions, synthesizing high purity UHTC powders with 
controlled particle sizes for infiltration processing, and increasing the elastic modulus of available fibers to promote load transfer from the brittle UHTC matrix to the reinforcing fiber. Computational materials research methodshave been applied to some UHTC systems. Several authors have predicted fundamental properties, thermodynamic stability, stable crystal structures, and deformation mechanisms for different boride, carbide, and nitride systems. For example, hardness and elastic constants have been predicted computationally in the search for ultra-hard, incompressible materials. ${ }^{6,71-74}$ Some initial studies of phase stability and deformation have been reported along with simulations related to thermal properties. ${ }^{75-}$ ${ }^{78}$ Challenges for computational investigations include definingaccurate interatomic potentials for UHTC systems, identifying properties that reflect intrinsic behavior of the materials rather than extrinsic factors for model validation, and extending simulations to ultra-high temperatures. More robust simulations of fracture behavior and transport properties are also needed to understand mechanisms at length scales ranging from atoms to the mesoscale.

The family of UHTCs being studied at the present time are essentially the same materials that were examined during the space race of the 1950s and 60s. Discovery of new materials is needed to expand the number of UHTCs and thereby broaden the number of potential applications for UHTCs.The likelihood that a large number of new UHTC compounds remains undiscovered seems extremely low, which means that research on new UHTCs will more likely follow the development of advanced structural metals. ${ }^{79,80}$ For example, opportunities exist to design second phase additions that could enable transformation toughening or inhibit creep deformation at elevated temperatures while simultaneously improving oxidation resistance. Likewise, additives that dissolve into the UHTC matrix and form solid solutions are another method by which properties might be manipulated. Our group has demonstrated that oxidation 
behavior at intermediate temperatures can be improved by adding transition metals such as $\mathrm{W}$, Ta, or Nb, but solution additives may also benefit strength and/or fracture toughness at room or elevated temperatures. ${ }^{81,82}$ Rather than conventional experimental approaches, the search for new UHTCs is likely to be driven by computational means and will likely require novel approaches such as exploring entropy-stabilization ${ }^{83}$ or other methods that have not yet been espoused. Such approaches have the potential to revolutionize the search for, not just new UHTCs, but all types of new materials.

Several new applications will also motivate future research on UHTCs. Whereas most of the discussion abovedescribed aerospace applications, UHTCs are also candidates for use in applications such as advanced nuclear fission reactors, ${ }^{84}$ high temperature electrodes for metal refining, ${ }^{85}$ high power-density microelectronics, ${ }^{86}$ concentrated solar power, ${ }^{87}$ fusion energy systems, ${ }^{88}$ and many others.In particular, nuclear applications have gained significant attention due to needs for accident-tolerant fuels andcladding, non-oxide fuel pellets, inert matrix fuels, waste separation, and moderators. ${ }^{89}$ A growing number of possible applications should lead to additional research in this area. Some of the anticipated challenges arecost, minimizing impurities, producing dense materials, and estimating performance lifetime.

\section{Summary and Outlook}

Significant research effort has gone into studying the fundamental properties of UHTCs. Revealingthe remarkable properties of UHTCs continues to broaden the possible range of potential applications. The initial motivation for UHTC research was centered on aerospace applications due to needs for materials with higher melting temperatures, improved thermal conductivity, mechanical stability, and resistance to the extreme heat fluxes and chemically 
reactive plasmas encountered during hypersonic flight and atmospheric re-entry. Presently, the range of potential applications for these materials is broadening to include the fields of energy (nuclear fission and fusion, energy harvesting, concentrated solar power), materials processing (high temperature electrodes, high speed machining tools, molten metal containment), microelectronics (conductors, barrier layers, lattice matched substrates), and others.

The lure of revolutionary advances in performance and the need to withstand increasingly extremeoperating conditions will continue to motivate research on UHTCs. Research efforts should evolve from the present focus on synthesis, processing, densification, structure-property relationships and oxidation to tackle challenges associated with performance in extreme environments, fiber-reinforced composites, computational studies, and new materials.By about 2020, the second wave of UHTC research will have been active for nearly 30 years, which is significant because this is the typical time required for a new class of materials to find its initial commercial applications. As UHTCs reach this milestone,potential funding sources will likely expand from the predominance of government funded efforts focused on basic research to include increasinglyapplied research and development efforts funded by companies and industrial consortia. Hence, the global research community that studies UHTCs should continue to grow as UHTCs transition from laboratory studies to real-world applications.

\section{Acknowledgement}

This work was supported by theUltra-High Temperature Materials Program in the Office

of Naval Research through grant N00014-16-1-2303.The guidance of program manager Dr. Eric Wuchina. This manuscript is based on a keynote presentation titled "Ultra-High Temperature 
Ceramics: Current Status and Emerging Trends" given by WGF at the $6^{\text {th }}$ International Ceramics Congress, Dresden Germany, August 22, 2016. 


\section{References}

1. E. Wuchina, E. Opila, M. Opeka, W. Fahrenholtz, I. Talmy, Electrochem. Soc. Interface, 16 (2007) 30

2. Ultra-High Temperature Ceramics: Materials For Extreme Environment Applications, W.G. Fahrenholtz, E.J. Wuchina, W.E. Lee, Y. Zhou (Eds.), Wiley, New York, 2014

3. W.G. Fahrenholtz, G.E. Hilmas, I.G. Talmy, J.A. Zaykoski, J. Am. Ceram. Soc. 90 (2007) 1347.

4. W. B. Hillig, Prospects for Ultrahigh-Temperature Ceramic Composites, in R.E. Tressler, G.L. Messing, C.G. Pantano, R.E. Newnam (eds.), Tailoring Multiphase and Composite Ceramics, Plenum Press, 1986, pp. 697-712.

5. M.M. Opeka, I.G. Talmy, E.J. Wuchina, J.A. Zaykoski, S.J. Causey, J. Euro. Ceram. Soc,, 19 (1999) 2405.

6. X. Zhang, X. Luo, J. Han, J. Li, W. Han, Comp. Mater. Sci. 44 (2008) 411

7. H. Moissan, Comptes Rendus Hebdomadaires des Seances de l’Academie des Sciences, 122 (1896) 651.

8. S.A Tucker, H.R. Moody, J. Chem. Soc., 81 (1902) 14.

9. E.S. Love, Introductory Considerations of Manned Reentry Orbital Vehicles, in: U.S. Air Force and National Aeronautics and Space Administration Joint Conference on Manned Hypervelocity and Reentry Vehicles: A Compilation of Papers Presented, NASA Report TMX 67563, Langley Research Center, Langley Field, VA, 1960, pp. 39-54

10. E.E. Mathauser, "Materials for Application to Manned Reentry Vehicles, in U.S. Air Force and National Aeronautics and Space Administration Joint Conference on Manned Hypervelocity and Reentry Vehicles: A Compilation of Papers Presented, NASA Report TMX 67563, Langley Research Center, Langley Field, VA, 1960, pp. 559-570

11. W.H. Steurer, R.M. Crane, L.L. Gilbert, C.A. Hermach, E. Scala, E.J. Zeilberger, R.H. Raring, Thermal Protection Systems: Report on the Aspects of Thermal Protection of Interest to NASA and the Related Materials R\&D Requirements, National Aeronautics and Space Administration, Washington DC, February 1962.

12. V.M. Vedula, Ultra-High Temperature Ceramic-Ceramic Composites, Final Report on Project WRDC-TR-89-4089, Air Force Materials Laboratory, Wright Patterson Air Force Base, Dayton, OH, October 1989.

13. E.L. Courtright, H.C. Graham, A.P. Katz, R.J. Kerans, Ultra-High Temperature Assessment Study-Ceramic Matrix Composites, Final Report WL-TR-91-4061, Wright Laboratory Materials Directorate, Wright Patterson Air Force Base, Dayton, OH, September 1992.

14. G.M. Mehrotra, Chemical Compatibility and Oxidation Resistance of Potential Matrix and Reinforcement Materials in Ceramic Composites for Ultra-High Temperature Applications, Final Report Number WRDC-TR-90-4127, Air Force Systems Command, Wright Patterson Air Force Base, Dayton, OH, March 1, 1991.

15. D. Rasky, J. Bull, Ultra-High Temperature Ceramics, NASA Report RTOP 232-01-04, May 2, 1994

16. D.M. Van Wie, D.G. Drewry, Jr., D.E. King, C.M. Hudson, J. Mater. Sci., 39 (2004) 5915.

17. M.M. Opeka, I.G. Talmy, Zaykowski, J. Materials Science 39 (2004) 5887.

18. E. Wuchina, M. Opeka, S. Causey, K. Buesking, J. Spain, A. Cull, J. Routbort, J. Mater. Sci. 39 (2004) 5939. 
19. R. Thomson, Production, Fabrication, and Uses of Borides, in: R. Freer (ed.), The Physics and Chemistry of Carbides, Nitrides and Borides, Kluwer Academic Publishers, Dordrecht, 1990, pp. 113-120.

20. E.K. Storms, The Refractory Carbides, Ch. 2: The Zirconium-Zirconium Carbide System, Academic Press, New York, 1967.

21. W.G. Fahrenholtz, J. Binner, J. Zou, J. Mater. Res.,31 (2016) 2757.

22. Y. Cao, H. Zhang, F. Li, L. Lu S. Zhang, Ceram. Int.41 (2015) 7823

23. Z. Xie, X. Deng, X. Suo, T. Zhou, Y. Gou, Mater. Chem. Phys., 159 (2015) 178

24. V.L. Wiesner, L.M. Rueschhoff, A.I. Diaz-Cano, R.W. Trice, J.P. Youngblood, Ceram. International, 42 (2016) 2750

25. C. Tallon, D. Chavara, A. Gillen, D. Riley, L. Edwards, S. Moricca, G.V. Franks, J. Am. Ceram. Soc., 96 (2013) 2374.

26. S.L. Natividad, V.R. Marotto, L.S. Walker, D. Pham, W. Pinc, E.L. Corral, J. Am. Ceram. Soc., 94 (2011) 2749

27. J.W. Zimmermann, G.E. Hilmas, W.G. Fahrenholtz, J. Am. Ceram. Soc. 92 (2009) 161

28. S. Baik, P.F. Becher, J. Am. Ceram. Soc. 70 (1987) 527.

29. S.C. Zhang, G. Hilmas, W.G. Fahrenholtz, J. Am. Ceram. Soc. 91(2008) 26

30. A.L. Chamberlain, W.G. Fahrenholtz, G.E. Hilmas, J. Am. Ceram. Soc. 89 (2006) 450

31. L. Silvestroni, D. Sciti, J. Kling, S. Lauterbach, H.-J. Kleebe, “J. Am. Ceram. Soc. 92 (2009) 1574.

32. J.-X. Liu, Y.-M. Kan, G.-J. Zhang, J. Am. Ceram. Soc. 92 (2010) 370

33. S. Guo, T. Nishimura, Y. Kagawa, Scripta Mater. 65 (2001) 1018

34. L. Zhang, D.A. Pejaković, J. Marschall, M. Gasch, J. Am. Ceram. Soc.94 (2011) 2562.

35. G. Harrington, G.E. Hilmas, W.G. Fahrenholtz, J. Euro. Ceram. Soc. 35 (2015) 887

36. D.L. McClane, W.G. Fahrenholtz, G.E. Hilmas, J. Am. Ceram. Soc., 97(2014) 1552

37. W.G. Fahrenholtz, J. Am. Ceram. Soc. 90 (2007) 143

38. T.A. Parasarathy, R.A. Rapp, M. Opeka, M.K. Cinibulk, J. Am. Ceram. Soc. 95 (2012) 338

39. E.W. Neuman, G.E. Hilmas, W.G. Fahrenholtz, J. Am. Ceram. Soc. 96 (2013) 47

40. E.W. Neuman, G.E. Hilmas, W.G. Fahrenholtz, J. Euro. Ceram. Soc. 33 (2013) 2889

41. E.W. Neuman, G.E. Hilmas, W.G. Fahrenholtz, J. Euro. Ceram. Soc. 35 (2015) 463

42. D.L. McClane, W.G. Fahrenholtz, G.E. Hilmas, J. Am. Ceram. Soc., 98 (2015) 637

43. J.M. Lonergan, W.G. Fahrenholtz, G.E. Hilmas, J. Am. Ceram. Soc. 97 (2014) 1689

44. G.J.K. Harrington, "Effect of Solid Solutions and Second Phases on the Thermal Conductivity of Zirconium Diboride Ceramics,” PhD Dissertation, Missouri University of Science and Technology, 2014

45. P. Hu, Z. Wang, J. Euro. Ceram. Soc., 30 (2010) 1021

46. J. Han, P. Hu, X. Zhang, S. Meng, W. Han, Composite Sci. Tech. 68 (2008) 799

47. H.F. Jackson. D.D. Jayaseelan, D. Manara, C.P. Casoni, and W.E. Lee, J. Am. Ceram. Soc., 94 (2011) 3561

48. A. Paul, J.G.P. Binner, B. Vaidhyanathan, A.C.J. Heaton, and P.M. Brown, Advances in Applied Ceram., 115 (2016) 158

49. M. Miller-Oana, P. Neff, M. Valdez, A. Powell, M. Packard, L.S. Walker, E.L. Corral, J. Am. Ceram. Soc., 98 (2015) 1300

50. H.A. Bale, A. Haboub, A.A. Macdowell, J.R. Nasiatka, D.Y. Parkinson, B.N. Cox, D.B. Marshall, R.O. Ritchie, Nat. Mater. 12 (2013) 40 
51. "Evaluation of the NASA Arc Jet Capabilities to Support Mission Requirements," NASA report number SP-2010-577.

52. B. Bottin, M. Carbonaro, S. Zemsch, G. Degrez, AIAA Paper 1997-2498

53. L. Charpentier, K. Dawi, J. Eck, B. Pierrat, J.-L Sans, M. Balat-Pichelin, J. Solar Energy Engineering, 133 (2011) 031005

54. T.A. Parthasarathy, M.K. Cinibulk, and M. Opeka, Modeling and Evaluations of Environmental Degradation of UHTCs under Hypersonic Flow, in: W.G. Fahrenholtz, E.J. Wuchina, W.E. Lee, Y. Zhou (eds.), Ultra-High Temperature Ceramics: Materials For Extreme Environment Applications, , Wiley, New York, 2014, pp. 267-290.

55. J. Eric, R.J. Hull, T.N. Johnson, D.R. Lovett, D.B. Seibert II, Proceedings of the 2007 International SAMPE Symposium and Exhibition, 52 (2007) 7

56. S. Rigney, D. Garrard, Proceedings of the $53^{\text {rd }}$ AIAA Aerospace Sciences Meeting, AIAA 2015-1784 (2015) 11

57. M.L. Mills, Proceedings of the $53^{\text {rd }}$ AIAA Aerospace Sciences Meeting, AIAA 2015-1336 (2015) 12

58. J.L. Wong, V. Jovanovic, I. Tang, R. Broeren, Proceedings of the $34^{\text {th }}$ Thermophysics Conference (2000).

59. D. Alfano, R. Gardi, L. Scatteia, and A. Del Vecchio, UHTC-Based Hot Structures: Characterization, Design, and On-Ground/In-Flight Testing, , in: W.G. Fahrenholtz, E.J. Wuchina, W.E. Lee, Y. Zhou (eds.), Ultra-High Temperature Ceramics: Materials For Extreme Environment Applications, , Wiley, New York, 2014, pp. 416-436.

60. E.L. Corral, L.S. Walker, J. Euro. Ceram. Soc., 30 (2010) 2357

61. A. Paul, J.G.P. Binner, B. Vaidhyanathan, A.C.J. Heaton, P.M. Brown, J. Microscopy 250 (2013) 122

62. H. Li, S. Li, L. Zhang, Y. Zhou, Ceram. Intl. 42 (2016) 5686

63. W. Tan, M. Adducci, R. Trice J. Am. Ceram. Soc., 97 (2014) 2639

64. L. Silvestroni, D. Dalle Fabbriche, C. Melandri, and D. Sciti, J. Euro. Ceram. Soc. 36 (2016) 17

65. A. Paul, S. Venugopal, J.G.P. Binner, B. Vaidhyanathan, A.C.J. Heaton, and P.M. Brown, J. Euro. Ceram. Soc., 33 (2013) 423

66. C.J. Leslie, E.E. Boakye, K.A. Keller, M.K. Cinibulk, Ceram. Trans. 240 (2013) 3

67. J.J. Sha, J. Li, S.H. Wang, Z.F. Zhang, Y.F. Zu, S. Flauder, W. Krenkel, Intl. J. Refract. Metal. Hard Mater. 60 (2016) 68

68. M. Kütemeyer, L. Schomer, T. Helmreich, S. Rosiwal, and D. Koch, J. Euro. Ceram. Soc., 36 (2016) 3647

69. L. Duan, L. Luo, Y. Wang, Mater. China 34 (2015) 762

70. W. Zhang, C. Wie, M. Ge, and X. Wei, C/C-ZrB $2-$ SiC Composites Derived from Polymeric Precursor Infiltration and Pyrolysis Part I: Preparation and Microstructures, in: I.M. Low, Y. Sakka, and C.F. Hu,MAX Phases and Ultra-High Temperature Ceramics for Extreme Environments, IGI Global, 2013, pp. 413-434.

71. N. Hamdad, N. Benosman, B. Bouhafs, Physica B 405 (2010) 540

72. H. Xiang, Z. Feng, Z. Li, and Y. Zhou, J. Appl. Phys., 117 (2015) 225902

73. M. Hebbache, L. Stuparevic, D. Zivkovic, Solid State Comm., 139 (2006) 227

74. Y.X. Wang, Appl. Phys. Lett., 91 (2007) 101904

75. X.-X. Yu, C. Weinberger, G.B. Thompson, Acta Mater., 80 (2014) 341 
76. T. Chakrabarti, L. Rangaraj, V. Jayaram, J. Mater. Res. 30 (2015) 1876

77. S. Kiani, J.-M. Yang, S. Kodambaka, J. Am. Ceram. Soc., 98 (2015) 2313

78. J.W. Lawson, C.W. Bauschlicher, Jr., M.S. Daw, J. Am. Ceram. Soc., 94 (2011) 3494

79. G. Ghosh, G.B. Olson, Acta Mater., 55 (2007) 3281

80. W.A. Counts, M. Friak, D. Raabe, J. Neugebauer, Acta Mater. 57 (2009) 69

81. S.C. Zhang, G.E. Hilmas, W.G. Fahrenholtz, J. Am. Ceram. Soc., 94 (2011) 1198

82. M.K. Dehdashti, W.G. Fahrenholtz, G.E. Hilmas, Corrosion Sci., 91 (2015) 211

83. C.M. Rost, E. Sachet, T. Borman, A. Moballegh, E.C. Dickey, D. Hou, J.L. Jones, S. Curtarolo, J.-P. Maria, Nature Comm., 6 (2015) 8485

84. I. Chant, K.L. Murty, J. Metals, 62 (2010) 67

85. G.B. Raju, B. Basu, Key Engin. Mater., 395 (2009) 89

86. Y.T. Hou, F.Y. Yen, P.F. Hsu, V.S. Chang, P.S. Lim, C.L. Hung, L.G. Yao, J.C. Jiang, H.J. Lin, Y. Jin, S.M. Jang, H.J. Tao, S.C. Chen, M.S. Liang, Technical Digest - International Electron Devices Meeting, IEDM article number 1609258, 2005 (2005) 31

87. E. Sani, L. Mercatelli, M. Meucci, A. Balbo, L., Silvestroni, D. Sciti, Solar Energy 131 (2016) 199

88. S.J. Zinkle, L.L. Snead, Annual Rev. Mater. Res., 44 (2014) 241

89. W.E. Lee, E. Giorgio, R. Harrison, A. Maitre, O. Rapaud, Nuclear Applications for UltraHigh Temperature Ceramics and MAX Phases, in:W.G. Fahrenholtz, E.J. Wuchina, W.E. Lee, Y. Zhou (eds.), Ultra-High Temperature Ceramics: Materials For Extreme Environment Applications, Wiley, New York, 2014, pp. 391-415. 
Figure Captions

Figure 1. Melting temperature for elements and compounds from different families of materials showing that very few materials have melting temperatures above $3000^{\circ} \mathrm{C}$. Reprinted by permission from [3].

Figure 2. Photograph of the $\mathrm{X}-51$ flight vehicle mounted on the wing of a $\mathrm{B}-52$ prior to a test flight.The $\mathrm{X}-51$ holds the record for the longest duration hypersonic flight by an aircraft. Note the heads of engineers on the lower left of the image for scale. Image is public domain from NASA.

Figure 3. Schematic of the two step process for the formation of $\mathrm{ZrB}_{2}$-SiC ceramics from a polymeric precursor showing that $\mathrm{ZrB}_{2}$ is formed by decomposing the polymeric precursor to $\mathrm{ZrO}_{2}$ and $\mathrm{C}$ followed by reaction with $\mathrm{B}_{2} \mathrm{O}_{3}$ to form $\mathrm{ZrB}_{2}$. Reprinted by permission from [22].

Figure 4. Comparison of microstructures of $\mathrm{ZrB}_{2}+30 \mathrm{vol} \% \mathrm{SiC}$ ceramics after pressureless sintering showing (left) low relative density ( $60 \%)$ and large particles $(>50 \mu \mathrm{m})$ with entrapped porosity produced by sintering without sufficient addtivies and (right) fully dense ceramic sintered with the addition of $\mathrm{B}_{4} \mathrm{C}$ and $\mathrm{SiC}$. Note the difference in magnification for the images. Reprinted by permission from [29].

Figure 5. Reported values for thermal conductivity as a function of temperature for a series of nominally pure $\mathrm{ZrB}_{2}$ ceramics showing that room temperature thermal conductivity for $\mathrm{ZrB}_{2}$ can vary from $\sim 30 \mathrm{~W} / \mathrm{m} \cdot \mathrm{K}$ to more than $130 \mathrm{~W} / \mathrm{m} \cdot \mathrm{K}$. Compiled using data from Guo, ${ }^{33}$ Zhang, $^{34}$ Harrington, ${ }^{35}$ and McClane. ${ }^{36}$

Figure 6. Schematic of the oxidation of a $\mathrm{TMB}_{2}$ ceramic containing SiC showing the formation of a scale containing the TM oxide and a borosilicate glassy layer, which recedes during oxidation at elevated temperatures. Reprinted by permission from [38] 


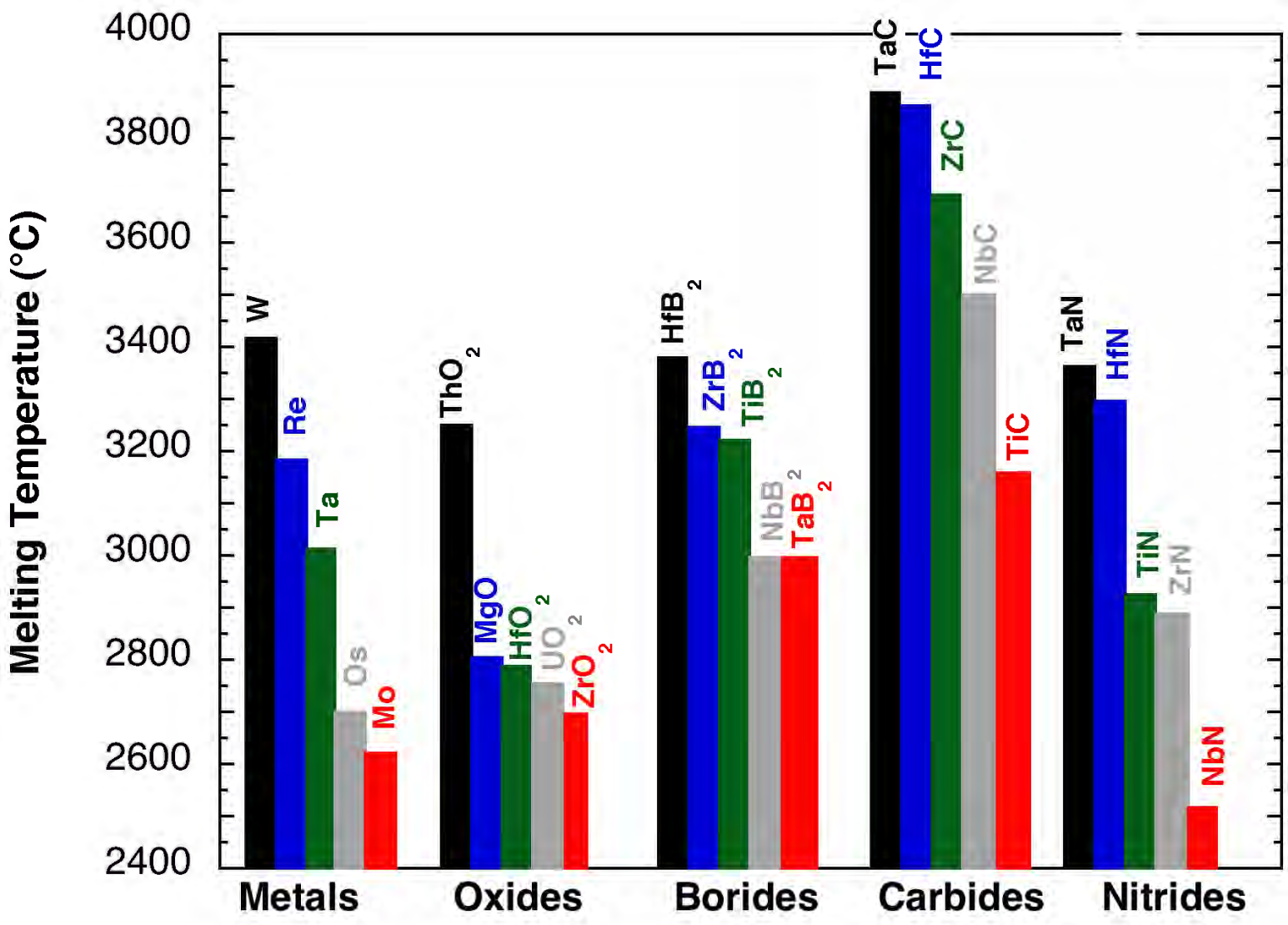




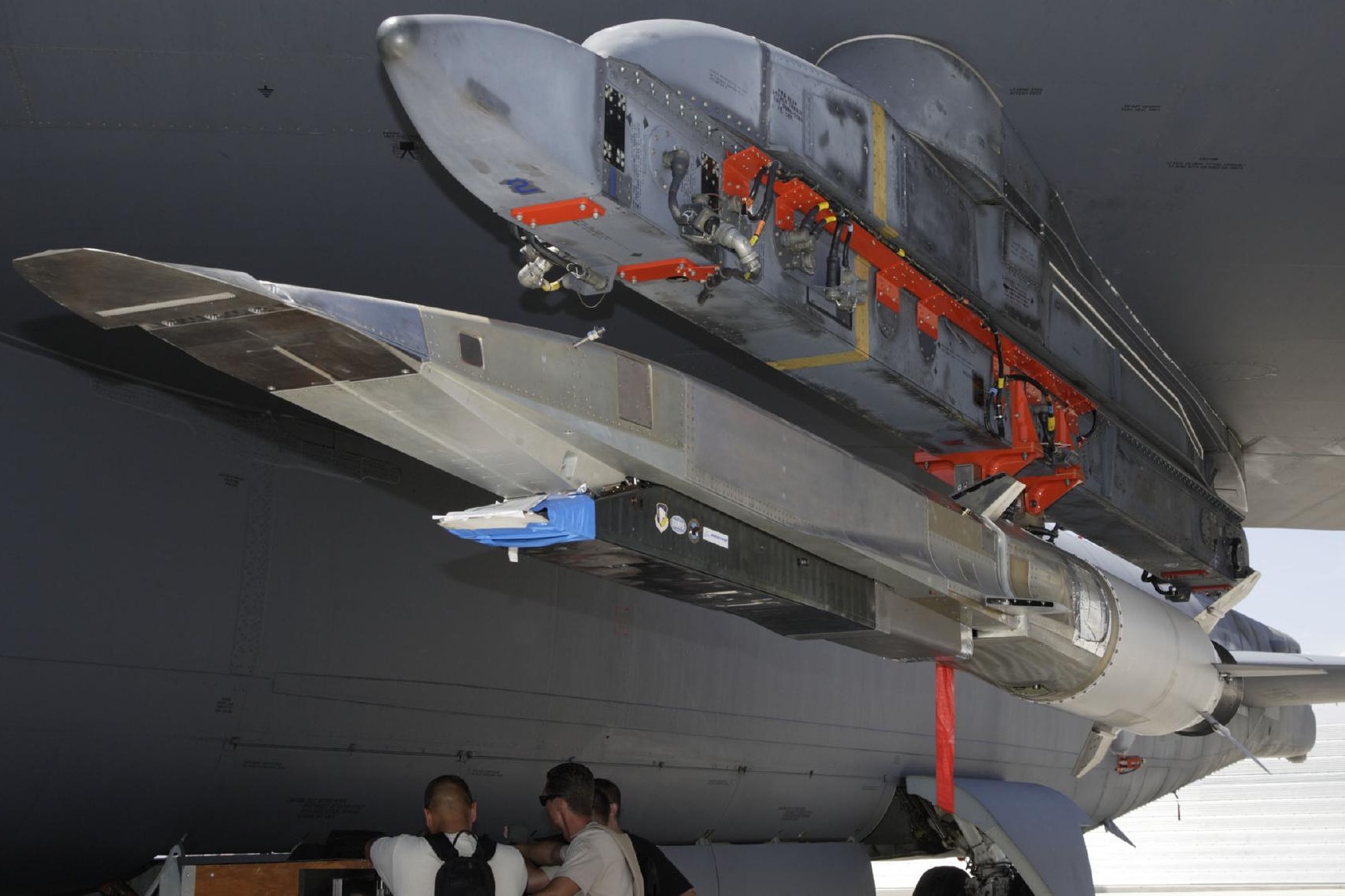





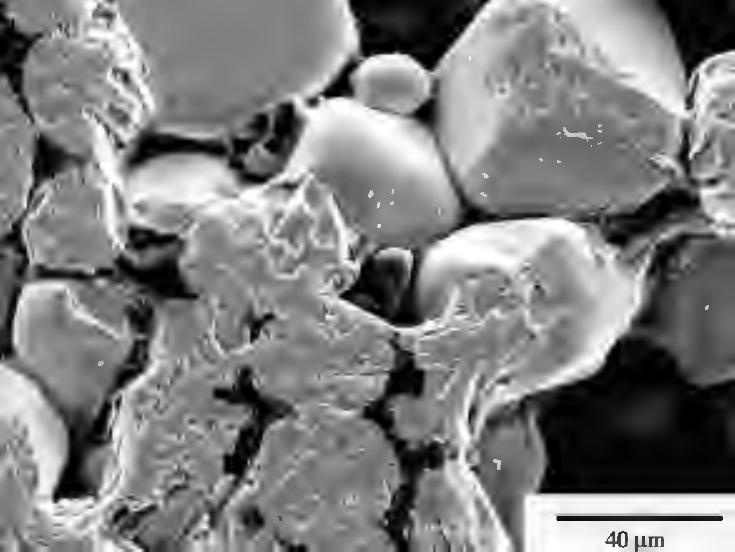




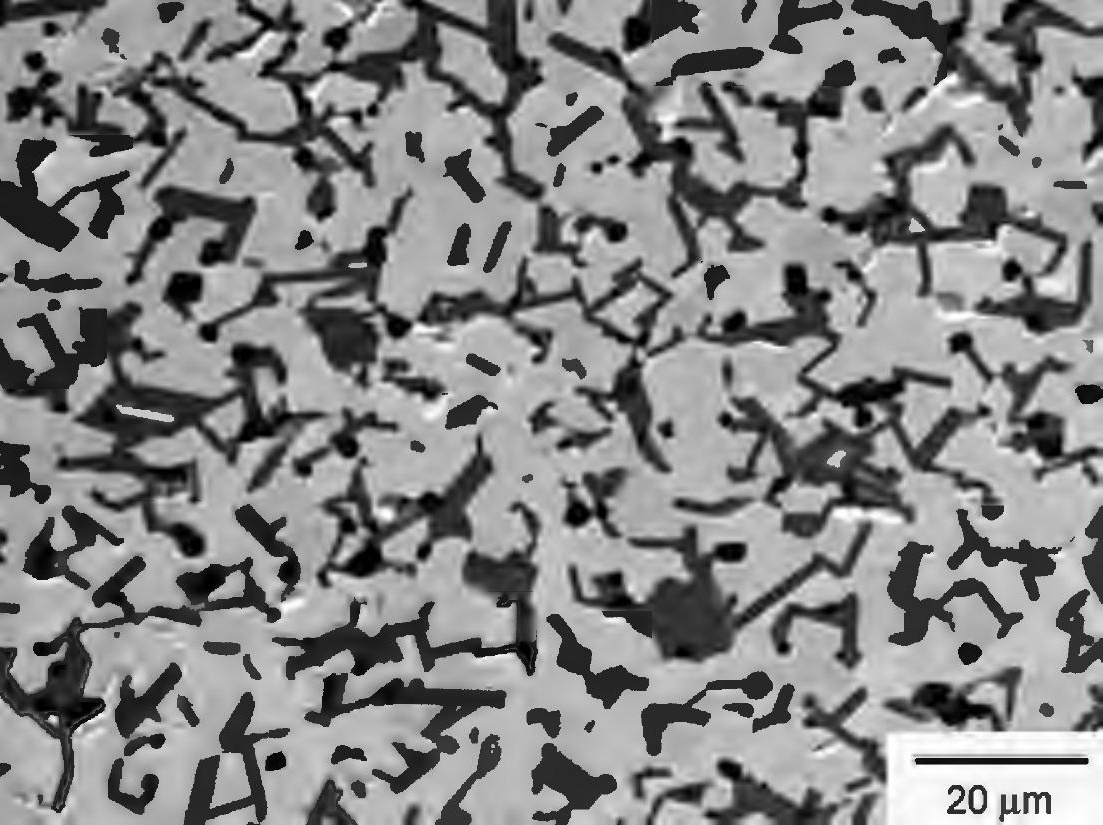




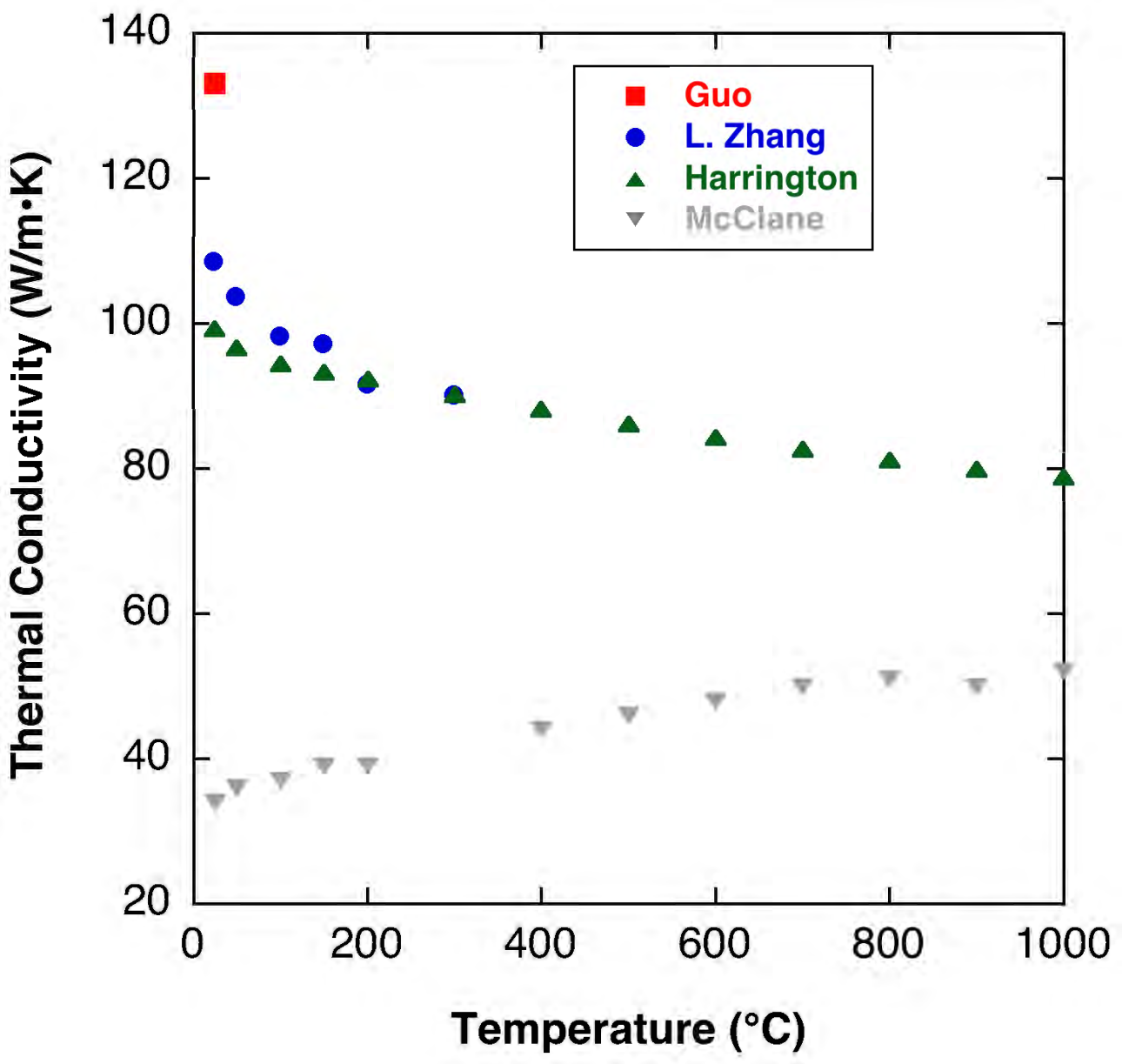




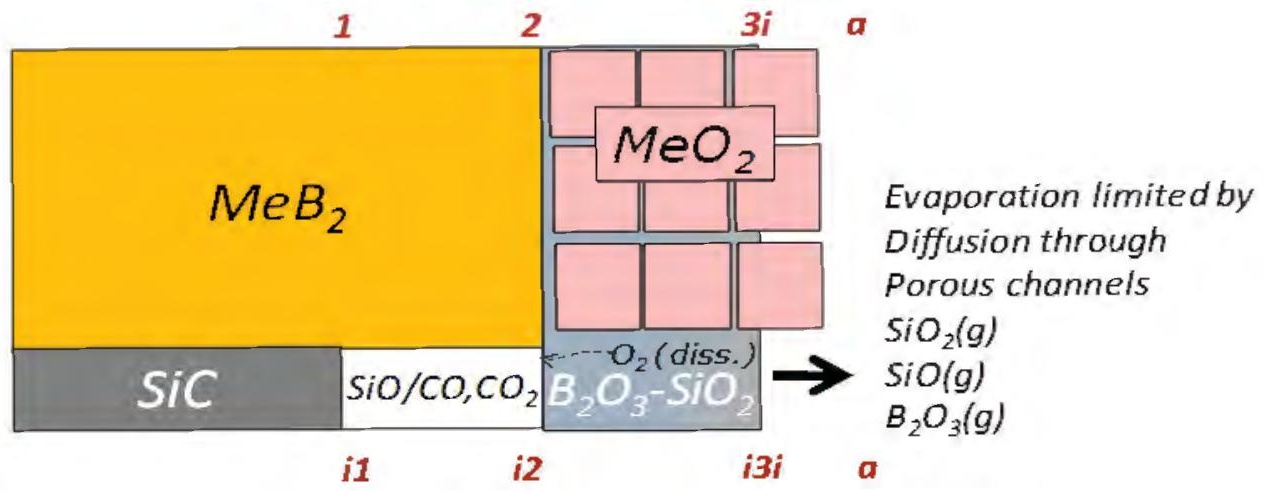

